\title{
Effect of Temperature and Preservative on Neo-ethanol Formation in Postmortem Whole Blood Samples
}

\author{
Shakeel Ahmad, Muhammad Aamir, Sobia Irum Kirmani, Zujaja Hina Haroon, Afshan Bibi and Usama Bin Khalid \\ Department of Chemical Pathology and Endocrinology, Armed Forces Institute of Pathology (AFIP), Rawalpindi, Pakistan
}

\begin{abstract}
Objective: To determine the association of temperature, time duration, and preservatives with ethanol neo-genesis in postmortem whole blood samples.

Study Design: Observational cross-sectional study.

Place and Duration of Study: Department of Chemical Pathology and Toxicology, Armed Forces Institute of Pathology, Rawalpindi, in collaboration with Combined Military Hospital, Rawalpindi from August 2020 to January 2021.

Methodology: Whole blood samples were obtained from cardiac chamber of an autopsy case with aseptic measures and were drawn into six tubes $\left(3 \times\right.$ EDTA tubes and $3 \times \mathrm{NaF}$ tubes). These six tubes were stored at $4^{\circ} \mathrm{C}, 25^{\circ} \mathrm{C}$, and $37^{\circ} \mathrm{C}$. All samples were analysed along with internal standard, on head space gas-chromatography on Day-0, Day-07, Day-14, Day-21, and Day-28 of sampling.

Results: A total of 60 samples out of 10 autopsies, were analysed. Blood alcohol concentrations of all samples were negative on $1^{\text {st }}$ day (Day-0) of analysis. Samples stored at $4^{\circ} \mathrm{C}$ did not produce any ethanol at any day of analysis, regardless of preservatives used. Neo-ethanol levels of blood samples stored in EDTA preservative were significantly raised $(p<0.001)$ as compared to samples stored in NaF preservative. Samples stored at $37^{\circ} \mathrm{C}$ showed significant increase in neo-ethanol concentration $(\mathrm{p}$ $<0.001$ ) in comparison with samples stored at $4^{\circ} \mathrm{C}$ and $25^{\circ} \mathrm{C}$. Neo-ethanol levels increased with duration of storage till $14^{\text {th }}$ day of analysis.

Conclusion: Sodium fluoride (NaF) should be used as preservative to avoid ethanol neo-genesis during storage and transportation of blood samples for alcohol analysis. Cold chain maintenance is of pivotal importance to exclude false positive blood alcohol results.
\end{abstract}

Key Words: Neo-ethanol, Neo-genesis, Ethylenediaminetetra acetic acid (EDTA), Sodium fluoride (NaF).

How to cite this article: Ahmad S, Aamir M, Kirmani SI, Haroon ZH, Bibi A, Khalid UB. Effect of Temperature and Preservative on Neoethanol Formation in Postmortem Whole Blood Samples. J Coll Physicians Surg Pak 2021; 31(10):1159-1162.

\section{INTRODUCTION}

Determination of blood alcohol concentration is of great importance in all autopsies and it is being used as evidence in a court of law. ${ }^{1}$ It must be ascertained that whether alcohol concentration measured in postmortem blood samples has resulted from antemortem ingestion of alcohol or formed postmortem. This new alcohol formed in postmortem blood sample is predominantly ethanol, known as neo-ethanol. ${ }^{2,3}$ Bacterial putrefaction is the main source of alcohol formation in postmortem blood samples, as a number of microbial species present in autopsy samples are capable of producing alcohol. ${ }^{4}$

Correspondence to: Dr. Shakeel Ahmad, Department of Chemical Pathology and Endocrinology, Armed Forces Institute of Pathology (AFIP), Rawalpindi, Pakistan E-mail: shakilahmad910@gmail.com

Received: June 30, 2021; Revised: August 04, 2021; Accepted: September 01, 2021

DOI: https://doi.org/10.29271/jcpsp.2021.10.1159
Postmortem samples that are stored under improper conditions for longer duration used to undergo putrefaction, resulting in neo-ethanol formation as the end product of bacterial fermentation. The concentration of neo-ethanol depends on type of microorganisms present, available substrates, presence of preservative, temperature and duration of storage. In badly decomposed and putrefied bodies, blood alcohol concentration is grossly raised. ${ }^{5}$

Preservatives like sodium fluoride (NaF) are used for storage and transportation of blood alcohol samples. $\mathrm{NaF}$ is a weak anticoagulant as well as antiglycolytic agent to preserve glucose. It is used at a concentration of $2 \mathrm{mg} / \mathrm{ml}$ of blood along with anticoagulants like oxalate. It inhibits glycolytic enzyme enolase and prevents glucose from utilisation in glycolysis, subsequently formation of pyruvate, ultimately preventing ethanol neo-genesis in postmortem blood samples. ${ }^{6}$ Maintenance of cold chain during transportation and storage is also of pivotal importance for postmortem blood alcohol analysis. When stored at $2-6^{\circ} \mathrm{C}$, least amount of alcohol is formed in blood as it keeps glycolytic pathway at lower limit and also minimises microbial growth. ${ }^{7}$ Blood alcohol analysis should be performed as soon as possible 
because alcohol levels decrease with time. ${ }^{8}$ Delay in blood alcohol analysis favours bacterial proliferation and putrefaction, resulting infalse positivity for blood alcohol presence. ${ }^{9}$

Alcohol analysis of postmortem blood samples is ordered in many circumstances and concentration of alcohol in blood is influenced by many factors including use of preservative, transportation and storage temperature as well as time duration till analysis. Reporting false positive alcohol levels has lifelong implications in medico-legal cases. Many studies are available on stored positive blood samples for alcohol analysis. ${ }^{10}$ However, no such study has been carried out in Pakistan on postmortem blood samples that can quantitate the effect of temperature, preservatives and duration of storage on neo-ethanol formation. In order to observe the effects of these factors on ethanol neo-genesis in postmortem blood samples, there is a need to carry out a study that can quantitate the results of these affecting factors on neo-ethanol formation in postmortem blood samples.

The aim of the current study was to determine the association of temperature, time duration, and preservatives with ethanol neo-genesis in postmortem whole blood samples.

\section{METHODOLOGY}

It was an observational study, conducted at the Department of Chemical Pathology and Toxicology, Armed Forces Institute of Pathology, Rawalpindi, with prior approval by the Ethical Committee.

A pilot study was conducted at the Department of Toxicology, prior to the initiation of the research study. Autopsy blood samples included in the study were from cases routinely autopsied at Hospital, after fulfilling the inclusion criteria as done by Boumba et al. ${ }^{11}$ Non-probability convenient sampling technique was used for sampling with consent of next of kin of the deceased. Autopsies of diabetics, septicemia, liver injury, putrefied bodies and those reported after six hours of death were excluded. A total of 10 autopsies were included, further divided into 60 whole blood samples. Samples were obtained from right ventricle of heart, while maintaining maximum aseptic measures to avoid contamination. Each postmortem blood sample was put into $3 \times$ tubes with ethylenediaminetetra acetic acid (EDTA) and $3 x$ tubes with NaF preservative, respectively. $\mathrm{NaF}$ was used at a concentration of $2 \mathrm{mg} / \mathrm{ml}$ of blood along with anticoagulants, i.e. oxalate. EDTA was used as disodium salt with effective concentration of $2 \mathrm{mg} / \mathrm{ml}$ of blood. Each sample collected was $5 \mathrm{ml}$ in quantity and covered with a layer of liquid paraffin to avoid evaporation of volatile gases. Samples were stored at $4^{\circ} \mathrm{C}, 25^{\circ} \mathrm{C}$ and $37^{\circ} \mathrm{C}$, respectively. Furthermore, samples were analysed on first day (Day-0), Day-07, Day-14, Day-21, and Day-28 for blood alcohol levels. Blood alcohol concentration of all samples was negative on Day-0. Each sample was processed with commercially prepared internal standard (methyl ethyl ketone $0.03 \%$ ) in a sealed vial and then run on head space gas-chromatography (Agilent tech 7890A, USA). Head space gas-chromatography is used for estimation of volatile organics in samples including blood alcohol analysis.

SPSS version 21 was used for data analysis and normality of distribution of the data was determined by Shapiro-Wilk test. Data being non-parametric, quantitative variables were expressed as median and IQR. Statistical comparisons were performed using Mann-Whitney U-test and Kruskal-Wallis test with level of significance at $p<0.05$ ( $95 \%$ confidence interval).

Table I: The effect of storage duration on neo-ethanol formation in different preservatives.

\begin{tabular}{|c|c|c|c|c|}
\hline \multirow{2}{*}{$\begin{array}{l}\text { Duration of } \\
\text { storage }\end{array}$} & \multirow[t]{2}{*}{$\mathbf{n}$} & $\begin{array}{l}\text { Neo-ethanol } \\
\text { concentration } \\
\text { mg/dl ( EDTA) }\end{array}$ & $\begin{array}{c}\text { Neo-ethanol } \\
\text { concentration } \\
\text { mg/dl ( NaF) }\end{array}$ & \multirow{2}{*}{$\begin{array}{c}\text { p-value } \\
\text { (Kruskal- } \\
\text { Wallis } \\
\text { test) }\end{array}$} \\
\hline & & $\begin{array}{c}\text { Median IQR } \\
\left(25^{\text {th }}-75^{\text {th }}\right)\end{array}$ & $\begin{array}{c}\text { Median IQR } \\
\left(25^{\text {th }}-75^{\text {th }}\right)\end{array}$ & \\
\hline Day-0 & 60 & $0.0(0.0-0.0)$ & $0.0(0.0-0.0)$ & \multirow{5}{*}{$<0.001$} \\
\hline Day-7 & 60 & $0.0(0.0-5.0)$ & $0.0(0.0-0.0)$ & \\
\hline Day-14 & 60 & $12.0(0.0-16.2)$ & $0.0(0.0-4.0)$ & \\
\hline Day-21 & 60 & $9.0(0.0-11.2)$ & $0.0(0.0-2.2)$ & \\
\hline Day-28 & 60 & $3.5(0.0-8.0)$ & $0.0(0.0-0.0)$ & \\
\hline
\end{tabular}

\section{RESULTS}

A total of 10 autopsies were included in this study, after fulfilling the inclusion criteria. All samples were negative for blood ethanol levels on Day-0 of analysis. One, out of 10 autopsies, did not yield any ethanol concentration till Day-28 of analysis. None of the postmortem blood samples produced any blood ethanol on any day of analysis at $4^{\circ} \mathrm{C}$ of storage. Whole blood samples preserved with EDTA showed significantethanol neo-genesis as compared NaF ( $p$-value $<0.001$ ). Maximum concentration of neo-ethanol was observed in postmortem whole blood samples stored with EDTA preservative at temperature $37^{\circ} \mathrm{C}$, on Day- 14 of analysis. Storage temperature of $37^{\circ} \mathrm{C}$ found out to be most favourable for ethanol neo-genesis. Neo-ethanol levels were noted high on $14^{\text {th }}$ day of analysis and then there was a decrease in trend of ethanol concentration as the time duration passed on, as shown in Table l.

Kruskal-Wallis test was applied to compare ethanol neo-genesis at different temperatures $\left(4^{\circ} \mathrm{C}, 25^{\circ} \mathrm{C}, 37^{\circ} \mathrm{C}\right)$ with different preservatives (NaF, EDTA). There was a significant difference $(p<0.05)$ in neo-ethanol formation in whole blood samples with $\mathrm{NaF}$ preservative at temperature $4^{\circ} \mathrm{C}, 25^{\circ} \mathrm{C}$ and $37^{\circ} \mathrm{C}$. Significant difference was also observed in neo-ethanol formation in whole blood samples, preserved in EDTA at temperature $4^{\circ} \mathrm{C}, 25^{\circ} \mathrm{C}$ and $37^{\circ} \mathrm{C}(p<0.001)$. Mann-Whitney U-test was applied to compare ethanol neo-genesis at temperatures $\left(0^{\circ} \mathrm{C}, 25^{\circ} \mathrm{C}, 37^{\circ} \mathrm{C}\right)$ in NaF preservative with ethanol neo-genesis at temperatures $\left(0^{\circ} \mathrm{C}, 25^{\circ} \mathrm{C}, 37^{\circ} \mathrm{C}\right)$ in EDTA preservative. There was a significant difference between ethanol concentration at same storage temperature $\left(25^{\circ} \mathrm{C}\right)$ with different preservatives $(p<0.05)$ as well as significant difference was observed in ethanol neo-genesis $(p<0.05)$ atstorage temperature $\left(37^{\circ} \mathrm{C}\right)$ in postmortem whole blood samples with $\mathrm{NaF}$ and EDTA preservatives. 
In order to observe the effect of storage duration on neo-ethanol formation in postmortem whole blood samples, Kruskal-Wallis test was applied to compare neo-ethanol concentration at different days (Day-0, Day-07, Day-14, Day-21, Day-28) of analysis. Significant difference was observed in ethanol concentration at different time duration of postmortem whole blood samples $(p<0.001)$ as shown in Tablel.

\section{DISCUSSION}

Estimation of blood ethanol levels is among one of the most important tasks for forensic toxicologist, as it can influence final decision making in a court of law. ${ }^{12}$ Ethanol can be endogenously formed from acetaldehyde that is being derived from variety of substrates. ${ }^{13}$ Ethanol production in postmortem whole blood sample is attributed to microbial consumption of available substrates, most importantly due to utilisation of carbohydrates. Microbial ethanol is produced by moulds and yeasts from glucose fermentation by using embden-meyerhof parnas (EMP) pathway and via hetero-fermentative pathway an-aerobically, by bacterial species. ${ }^{14}$ In this study, ethanol levels were negative on the first day of analysis of postmortem whole blood samples but with the passage of time, majority of samples turned positive for ethanol levels. A study carried out by Boumba et al. concluded that postmortem samples with E.coli produced no alcohol levels on Day-1 of storage and later turned positive for ethanol, suggestive of neo-ethanol formation in stored blood. ${ }^{15}$ The present authors included putrefaction-free autopsies on the basis of external examination, which can be misleading while interpreting neo-ethanol presence. Vassiliki et al. revealed that majority of their samples, which turned out to be putrefied on the basis of 1-Propanol levels in postmortem blood as marker of microbial ethanol production, presented without signs of putrefaction and yielded neoethanol on analysis. 1-propanol levels can be used to exclude postmortem putrefaction and while commenting on neoethanol presence in postmortem whole blood samples. ${ }^{11}$

Storage temperature plays a key role in maintaining the integrity of postmortem whole blood sample. Henceforth, temperature was found to affect ethanol neo-genesis during storage of blood samples. The samples stored at $4^{\circ} \mathrm{C}$ produced no ethanol at all and samples stored at $37^{\circ} \mathrm{C}$ manifested maximum ethanol neo-genesis. The study of Amick et al. on whole blood samples, inoculated with Saccharomyces cerevisiae, concluded that ethanol was produced at $37^{\circ} \mathrm{C}$ when blood samples were stored till Day-17 of sampling, in coherence with the findings of the present study. ${ }^{7}$ Postmortem whole blood samples stored at $4^{\circ} \mathrm{C}$ remained stable throughout the duration of this study, substantiated by the similar findings by Wongchanapai et al. ${ }^{16}$ In a study conducted by Sing et al. on ethanol neo-genesis in stored blood, no ethanol was formed in blood stored at $4^{\circ} \mathrm{C}$ till Day-42 of analysis of samples; whereas, maximum ethanol neo-genesis took place in samples preserved at $37^{\circ} \mathrm{C}$, thus corroborating the findings of the present authors. ${ }^{17}$ Lekskulchai et al. described false low detectable levels of ethanol in all blood samples stored at room temperatures before analysis; ${ }^{18}$ whereas, Laurens et al. concluded that blood sample stored at $4{ }^{\circ} \mathrm{C}$ remained stable throughout the study duration, irrespective of the presence orabsence of preservative. ${ }^{19}$

Preservatives are other pre-analytical factors that can influence ethanol levels, especially when sample is not stored at low temperature. This has been noted in this study, that whole blood samples stored with NaF preservative showed least ethanol neo-genesis and remained stable as compared to blood samples stored with EDTA preservative, likely attributed to the inhibitory effect of NaF on glycolytic pathway of carbohydrates metabolism. Other researchers also reported that samples with $\mathrm{NaF}$ preservative has a stabilising effect on ethanol concentration with least chances of ethanol neo-genesis. ${ }^{17,19}$ Lewis et al. revealed that addition of $\mathrm{NaF}$ to postmortem blood samples prevented the formation of ethanol at low storage temperatures. ${ }^{20}$ However, Penetar et al. concluded that storage condition including use of preservative, did not affect ethanol levels in their study. ${ }^{21}$

In the present study, neo-ethanol levels were high on Day-14 of analysis, and then tend to decrease with storage till Day-28 of analysis, an effect which was also reported by Wongchanapai et al. and Ferrari et al. ${ }^{14,22}$ This decrease in ethanol concentration is attributed to its oxidation by microbes. ${ }^{23}$

Addition of preservative ( $\mathrm{NaF}$ ) and storage temperature affected neo-ethanol levels in the present samples. Keeping in view the results of this study, neo-ethanol formation must be kept in mind while commenting on ethanol levels in stored blood. As per the results of this study and available literature data, whole blood sample for alcohol analysis, should always be stored and transported at low temperature. NaF tube should be used as preservative to maintain the integrity of blood sample tillalcohol analysis. Pre-analytical factorsare ofimmenseimportance while commenting upon the blood alcohol levels in postmortem samples. ${ }^{19}$

\section{CONCLUSION}

Storage temperature and presence of preservative are two key factors that affect ethanol neo-genesis during transportation and storage. Neo-ethanol formation can be kept at minimum by storageat lowtemperatureand byadding appropriate preservative (NaF).

\section{RECOMMENDATION:}

As per the results of this study and available literature data, whole blood sample for alcohol analysis, should always be stored and transported at a temperature as low as possible. $\mathrm{NaF}$ tube should be used as preservative to maintain the integrity of blood sampletill alcohol analysis.

\section{ETHICALAPPROVAL:}

Ethical approval was taken from Armed Forces Institute of Pathology Ethical Committee prior to research work. 


\section{PATIENT'S CONSENT:}

Written consent was taken from next of kin (NOK) of deceased included in ourstudy.

\section{CONFLICT OF INTEREST:}

The authors declared no conflict of interest.

\section{AUTHORS' CONTRIBUTION:}

SA: Idea conception, data collection, analysis, discussion and literature review.

MA: Data analysis, statistical review, discussion and literature review.

SIK: Data collection, discussion and literature review.

$\mathrm{ZHH}, \mathrm{AB}, \mathrm{UBK}$ : Statistical review, discussion and literature review.

\section{REFERENCES}

1. Ehmke-Engelbrecht U, du Toit-Prinsloo L, Deysel C, Jordaan J, Saayman G. Combating drunken driving-questioning the validity of blood alcohol concentration analysis. South African crime quarterly 2016; 57:7-14.

2. Boumba VA, Economou V, Kourkoumelis N, Gousia P, Papadopoulou C, Vougiouklakis T. Microbial ethanol production: Experimental study and multivariate evaluation. Forensic Sci Int 2012; 215(1-3):189-98. doi: 10.1016/j.forsciint.2011.03.003.

3. Takayasu T, Ohshima T, Tanaka N, Maeda H, Kondo T, Nishigami J, et al. Postmortem degradation of administered ethanol-d6 and production of endogenous ethanol: Experimental studies using rats and rabbits. Forensic Sci Int 1995; 76(2):129-40. doi: 10.1016/0379-0738(95)01807-7.

4. O'Neal CL, Poklis A. Postmortem production of ethanol and factors that influence interpretation: A critical review. Am J Forensic Med Pathol 1996; 17(1):8-20. doi: 10. 1097/ 00000433-199603000-00002.

5. Santunione AL, Verri P, Marchesi F, Rustichelli C, Palazzoli $F$, Vandelli $D$, et al. The role of ethyl glucuronide in supporting medico-legal investigations: Analysis of this biomarker in different postmortem specimens from 21 selected autopsy cases. J Forensic Leg Med 2018; 53: 25-30. doi: 10.1016/ j.jflm.2017.10.009.

6. Sutlovic D, Versic-Bratincevic M, Definis-Gojanovic M. Blood alcohol stability in postmortem blood samples. Am J Forensic Med Pathol 2014; 35(1):55-8. doi: 10.1097/PAF.0000000000000077.

7. Amick GD, Habben KH. Inhibition of ethanol production by Saccharomyces cerevisiae in human blood by sodium fluoride. J Forensic Sci 1997; 42(4):690-2. PMID: 9243833.

8. Dinis-Oliveira RJ. Oxidative and non-oxidative metabolomics of ethanol. Curr Drug Metab. 2016; 17(4): 327-35. doi: 10.2174/138920021766616012 5113806 .

9. Dinis-Oliveira RJ, Vieira DN, Magalhães T. Guidelines for collection of biological samples for clinical and forensic toxicological analysis. Forensic Sci Res. 2017; 1(1):42-51. doi:10.1080/20961790.2016.1271098.

10. Athanaselis S, Stefanidou M, Koutselinis A. Interpretation of postmortem alcohol concentrations. Forensic Sci Int 2005; 149(2-3):289-91. doi: 10.1016/j.forsciint.2003.04.001.

11. Boumba VA, Kourkoumelis N, Ziavrou K, Vougiouklakis T. Estimating a reliable cutoff point of 1-propanol in postmortem blood as marker of microbial ethanol production. J Forensic Sci Med 2019; 5:1416. http://www.jfsmonline. com/text.asp?2019/5/3/141/267156.

12. Chung J, Lee Y. Alcohol, deterrence, and crime: Causality and policy lessons from Korea. Policy Studies 2021. Published online: 10 May 2021. doi.org/10.1080/ 01442872.2021

13. Ostrovsky YM. Endogenous ethanol - Its metabolic, behavioral and biomedical significance. Alcohol 1986; 3(4): 239-247. doi.org/10.1016/0741-8329(86)90032-7.

14. Gottschalk G. Bacterial Metabolism. 2nd Edition, SpringerVerlag, New York. 1986; 208-80. dx.doi.org/10.1007/ 978-1-4612-1072-6.

15. Boumba VA, Kourkoumelis N, Gousia P, Economou V, Papadopoulou C, Vougiouklakis T. Modeling microbial ethanol production by $\mathrm{E}$. coli under aerobic/anaerobic conditions: applicability to real postmortem cases and to postmortem blood derived microbial cultures. Forensic Sci Int 2013; 232(1-3):191-8. doi: 10.1016/j.forsciint.2013. 07.021.

16. Wongchanapai W, Dokpuang D, Sasithonrojanachai S, Tamtakerngkit S. Stability of postmortem blood ethanol under experimental conditions. Siriraj Med J 2008; 60(1):62-5.

17. Singh K, Malik R and Katyal LK. Ethanol neogenesis in stored blood. J Forensic Gen Sci 2018; 1(3):30-37.

18. Lekskulchai V. Accuracy of VITROS alcohol analysis for post-mortem specimens. Australian J Forensic Sci 2014; 46(4): 433-441, doi: 10.1080/00450618.2014.891653.

19. Laurens JB, Sewell FJJ, Kock MM. Pre-analytical factors related to the stability of ethanol concentration during storage of ante-mortem blood alcohol specimens. J Forensic Leg Med 2018; 58:155-63. doi: 10.1016/j.jflm.2018.06.003.

20. Lewis RJ, Johnson RD, Angier MK, Vu NT. Ethanol formation in unadulterated postmortem tissues. Forensic Sci Int 2004; 146(1):17-24. doi: 10.1016/j.forsciint.2004.03.015.

21. David MP, Jane FM, Elizabeth TR and Scott EL. Comparison among plasma, serum, and whole blood ethanol concentrations: Impact of storage conditions and collection tubes. J Analytical Toxicol 2008; 32(7):505-10. 10.1093/ jat/32.7.505.

22. Ferrari LA, Triszcz JM, Giannuzzi L. Kinetics of ethanol degradation in forensic blood samples. Forensic Sci Int 2006; 161(2-3):144-50. doi: 10.1016/j.forsciint. 2006. 02.049 .

23. Corry JE. A review. Possible sources of ethanol ante- and post-mortem: its relationship to the biochemistry and microbiology of decomposition. J Appl Bacteriol 1978; 44(1):1-56. doi: 10.1111/j.1365-2672.1978.tb00776.x. 